\title{
Descrição de nomes contáveis e massivos em Parkatêjê
}

\author{
Ingryd Moraes de Moraes Lira \\ Universidade Federal do Pará, Brasil \\ https://orcid.org/0000-0002-8511-671X \\ Marília de Nazaré de Oliveira Ferreira \\ Universidade Federal do Pará, Brasil \\ https://orcid.org/0000-0001-9995-1938
}

\begin{abstract}
This paper investigates the distribution of count and mass nouns in Parkatêjê. We explored the distribution of number marking, numerals, and quantifiers in the language in constructions with count and mass nouns. Based on data from interviews in Parkatêjê communities, we show that we can distinguish count from mass nouns based on the distribution of numerals and quantifiers. While numerals can be directly combined with numerals, mass nouns require a container/measure phrase in such constructions. Our description of the distribution of quantifiers has shown that some quantifiers can be combined with all nouns; others occur only in constructions with count nouns and others occur only in constructions with mass nouns. The distribution of the plural morpheme is restricted to human nouns. As such, plurals do not distinguish count from mass nouns. Finally, based on Chierchia's 2010 proposal, we conclude that Parkatêjê presents characteristics of number marking and number neutral languages.
\end{abstract}

KEYWORDS: Parkatêjê language; Count nouns; Mass nouns; Numerals; Quantifiers; Plural

RESUMO: Neste trabalho apresentamos a distribuição de nomes contáveis e massivos em Parkatêjê. Analisamos a distribuição de marcação de número, numerais e quantificadores em construções com nomes contáveis e massivos. Com base em dados de entrevistas em comunidades Parkatêjê, mostramos que podemos distinguir nomes contáveis de nomes massivos com base na distribuição de numerais e quantificadores. Embora os numerais possam ser combinados diretamente aos numerais, os nomes massivos requerem uma unidade de contagem/medida nessas construções. Nossa descrição da distribuição de quantificadores mostrou que alguns quantificadores podem ser combinados com todos os nomes; outros são usados especificamente com nomes contáveis e outros são usados apenas com nomes massivos. A distribuição do morfema plural é restrita aos nomes humanos. Desta forma, a distribuição do plural não é um aspecto da língua que pode ser usado para distinguir nomes contáveis de nomes massivos. Por fim, com base na proposta de Chierchia de 2010, concluímos que Parkatêjê apresenta características tanto de línguas de número marcado como de línguas de número neutro. PALAVRAS-CHAVE: Língua Parkatêjê; Nomes contáveis; Nomes massivos; Numerais; Quantificadores; Plural

\section{Introdução}

Rothstein e Lima (2018: 2-3) apresentam uma revisão da literatura sobre os sistemas de reconhecimento e compreensão de quantidades e explicam que "há dois sistemas principais de reconhecimento e compreensão de quantidades: o sistema numérico aproximado Approximate Number System (ANS) e o paralelo sistema de individuação - Parallel Individuation System (PI)". O primeiro é um mecanismo associado à nossa capacidade de representar quantidades aproximadas e o segundo à nossa capacidade de rastrear itens individuais e pequenas pluralidades. A revisão bibliográfica apresentada pelas autoras sugere que já está estabelecido que bebês pré-verbais, assim como outras espécies (primatas não humanos), compartilham desses dois sistemas principais de reconhecimento numérico não verbal. Em consonância com essa ideia, observa-se por meio da literatura a respeito deste tema que a maioria das línguas naturais possui termos específicos para expressar quantidade (exata 
ou aproximada), muitas vezes, manifestados linguisticamente por intermédio de quantificadores e numerais, por exemplo.

Paralelamente a isso, os nomes são subdivididos tradicionalmente em nomes contáveis e massivos. Cruse (2011) afirma que nomes contáveis são aqueles que se manifestam em unidades discretas, delimitadas, as quais, em um primeiro momento, podem receber marca de contagem. Já os nomes massivos não se manifestam por unidades e se caracterizam como um referente cujo conteúdo denota massa ilimitada, material indiferenciado. Estes últimos, por se manifestarem de forma ilimitada e indiferenciada, não denotam precisão de quantidade, sendo, muitas vezes, necessária a inserção de expressões de medida. O referido autor ressalta que são conceitos que nem sempre refletem a realidade.

Partindo-se do pressuposto de que as línguas naturais apresentam distinções entre nomes que são passíveis de contagem e aqueles que não são, Chierchia (2010) propôs a existência de três tipos de língua: (1) línguas com marcação de número: caracterizam-se por distinguir nomes contáveis e nomes massivos por meio de critérios na utilização da marca de plural, de numerais e de quantificadores; (2) línguas com classificadores: distinguem tais nomes por meio de classificadores, isto é, há aqueles que ocorrem exclusivamente com contáveis e outros somente com massivos, por exemplo; e (3) línguas de número neutro: caracterizam-se por não apresentarem marcação morfológica de número e seus argumentos serem nus; neste último tipo de língua, a classe de numerais funciona como uma propriedade distintiva entre nomes contáveis e nomes de massa.

A marcação de número, o uso de numerais, quantificadores e classificadores são alvos de discussão, haja vista que estes são, muitas vezes, os principais critérios utilizados para distinguir esses nomes. Nesse sentido, buscamos, no presente estudo, analisar o comportamento da classe nominal em Parkatêjê, a fim de verificar: 1) se ocorrem na língua; 2) se, de alguma forma, os nomes se diferem quando combinados a alguns dos elementos supramencionados; e 3) se tais elementos podem ou não ser considerados critérios de distinção contável-massivo.

A metodologia da presente pesquisa foi baseada, principalmente, em Lima (2014). A referida autora desenvolveu um estudo sobre contagem e individuação em Yudja (Juruna, Tupi). Com base nos métodos e materiais utilizados por ela, foram feitas coletas de dados com falantes nativos da língua Parkatêjê. Utilizou-se como suporte um questionário de distinção contável-massivo elaborado por Lima e Rothstein (2020: 174-218), cujas etapas estão descritas a seguir.

- $1^{\text {a }}$ etapa: identificação de nomes referentes a várias categorias, como artefatos, animais, humanos, frutas, vegetais, substâncias líquidas, substâncias pastosas, substâncias granuladas e coletivos.

- $2^{\text {a }}$ etapa: identificação dos numerais existentes na língua por meio da contagem de conjuntos, tanto de material com formas e limites precisos quanto de substâncias que não apresentam tais características.

- $3^{\text {a }}$ etapa: identificação de marca de plural e testes para averiguar a possibilidade de sua combinação com diversas categorias de nomes.

- $4^{a}$ etapa: identificação de quantificadores e testes para averiguar a possibilidade de sua ocorrência com diversas categorias de nomes.

- $5^{\mathbf{a}}$ etapa: identificação de sintagmas-recipiente e testes para averiguar a possibilidade de sua ocorrência com diversas categorias de nomes.

- $6^{\mathbf{a}}$ etapa: percepção dos falantes em relação ao todo ou partes de um mesmo elemento. 
Por meio dos dados obtidos, procedeu-se a análise e o levantamento de hipóteses, que, posteriormente, vieram a ser refutadas ou confirmadas com uma nova coleta de dados com falantes nativos da língua.

A seguir, apresentamos uma breve explanação sobre a língua e o povo Parkatêjê, bem como descrevemos o sistema numérico da língua, a marcação de número e os quantificadores. Além disso, discutimos sucintamente sobre a ausência de classificadores e a presença de termos de classe na língua. Por fim, apresentamos os resultados da pesquisa.

\section{A língua e o povo Parkatêjê}

A língua Parkatêjê faz parte do tronco linguístico Macro-Jê, Família Jê, Complexo Dialetal Timbira (Rodrigues 1986: 56). Trata-se de uma língua em estado de obsolescência, visto que atualmente é falada apenas por um pequeno grupo, especificamente, os mais velhos. O povo, denominado Parkatêjê, também é conhecido pela denominação "Gavião Parkatêjê". Eles vivem na Reserva Indígena Mãe Maria, situada ao longo da BR-222, no município de Bom Jesus do Tocantins, no estado do Pará.

Os dados aqui apresentados foram coletados com o auxílio de colaboradores bilíngues, falantes nativos da língua Parkatêjê. Entrevistamos sete no total. Entre eles, dois atuam como professores na Escola Indígena de Ensino Fundamental Pẽmptykre Parkatêjê e ministram a disciplina específica sobre a cultura e língua Parkatêjê.

Discutiremos adiante sobre o sistema numérico da língua e sua ocorrência com os nomes.

\section{Sistema numérico}

Conforme Araújo (1989: 64), Parkatêjê apresenta numerais cardinais de um a três (pitfit 'um'; ajkrut 'dois'; e hitô 'três'), o que demonstra, segundo ela, um sistema pouco produtivo de numerais. A autora acrescenta que os termos oriundos dessa classe se comportam como adjetivos descritivos e posicionam-se em posição posterior aos nomes que determinam.

Ferreira (2003: 90) também descreve como numerais cardinais na referida língua pitfit 'um', ajkrut 'dois' e hitô 'três'. Para ela, esses termos não são adjetivos: "por suas características, os descritivos não apresentam propriedades morfológicas e sintáticas peculiares que permitam suficientemente seu tratamento como uma classe de adjetivos".

Considerando-se que os numerais apresentam, em muitas línguas, comportamentos distintos quando relacionados a nomes contáveis e a nomes de massa, buscou-se averiguar a ocorrência e comportamento destes com diferentes nomes na língua Parkatêjê como, por exemplo, kôkôy 'macaco', que neste estudo foi analisado como contável.

$\begin{array}{lllll}i- & \text { te } & \text { kôkôy } & \text { hitô } & \text { pupũn } \\ 1- & \text { ERG } & \text { macaco } & \text { três } & \text { ver+PST } \\ \text { 'Eu vi três macacos' } & & \end{array}$

Constatou-se, em Parkatêjê, que nomes de massa podem ser combinados com numerais nos seguintes contextos específicos: (i) quando há inserção de um recipiente de medida entre o nome e o numeral (2), (3) e (4); e (ii) quando o recipiente de medida está subtendido no contexto $^{1}(5),(6)$ e (7).

\footnotetext{
${ }^{1}$ Durante as coletas de dados, os consultores explicaram que, em algumas situações, o recipiente de medida, como o cofo, por exemplo, está presente fisicamente na situação comunicativa. Exemplo de situação:
} 
2) têrêre kàhà pitfit

açaí cesto um

'um cesto de açaí'

(3) têrêre kàhà ajkrut

açaí cesto dois

'dois cestos de açaí'

(4) têrêre kàhà hitô

açaí cesto três

'três cestos de açaí'

(5) $\quad k \hat{o} \quad[k \hat{o k o ̂ n o r e ~}]^{2} \quad$ pitfit

água cabaça um

'uma (cabaça) de água'

(6) kô [kôkônõre] ajkrut

água cabaça duas

'duas (cabaças) de água'

(7) kô [kôkônõre] hitô

água cabaça três

'três (cabaças) de água'

Na próxima seção, abordaremos a marcação de número em Parkatêjê e veremos que sua ocorrência é irrelevante em relação à distinção entre nomes contáveis e massivos.

\section{Marcação de plural}

Nos dados analisados da língua Parkatêjê, observou-se a ocorrência de um marcador de plural, mẽ , combinado com nomes relacionados a humanos.

(8)
$m p \dot{t}$
$m \tilde{u} \quad m \tilde{o}$
homem
$Q^{3} \quad$ ir
'O homem foi embora'

um índio está com o cofo na mão e pergunta "quantos devo trazer"? a algum outro índio. Este, por sua vez, por meio dos gestos e visualização do cenário ao redor, consegue inferir que o questionamento "quantos devo trazer"? se refere à quantidade de cofos. Neste caso, o numeral é usado para se referir à quantidade de cofos e não para a quantidade do elemento que está contido nele.

${ }^{2}$ Os colchetes indicam, neste trabalho, os elementos subtendidos no contexto de uso de língua e que não foram pronunciados na situação comunicativa.

${ }^{3}$ Partícula de verbos ativos. As demais glosas apresentadas que não constam no Leipzig Glossing Rules serão evidenciadas em notas de rodapé. 
(9)

$m \tilde{e} \quad m p \dot{i} \quad m \tilde{u} \quad m \tilde{o}$

PL homem Q ir

'Os homens foram embora'

(10) ntia mũ mõ kokrën

mulher Q ir cedo

'A mulher foi embora cedo'

(11) mẽ ntia mũ mõ kokrën

PL mulherQ ir cedo

'As mulheres foram embora cedo'

Ferreira (2003: 56) afirma que os nomes referentes a humanos recebem a marca $m \tilde{e}$, cujo sentido está vinculado ao plural, isto é, concepção da existência de dois ou mais elementos. $\mathrm{O}$ uso de $m \tilde{e}$ com nomes sem o referido traço tornam a construção agramatical.

Contexto: um índio se cortou, saiu muito sangue do ferimento e sujou o chão. Alguém pede para limpar e o outro pergunta: limpar o quê?
a. pika kaprô
chão sangue
'sangue no chão'
b. *pika me kaprô
chão PL sangue

Contexto: um índio, andando pelo mato, avistou três macacos. Ao chegar na aldeia, diz o que viu no mato.
a. $\quad i-\quad t \varepsilon \quad k \hat{o} k \hat{y} y$ hitô pupũn
1- ERG macaco três ver+PST
'Eu vi três macacos'
b. $\quad *_{i-} \quad t \varepsilon \quad m \tilde{e}$ kôkôy hitô pupũn
1- ERG PL macaco três ver+PST

Conclui-se, portanto, que nomes que não fazem referência a humanos apresentam outras estratégias para a marcação da forma plural na referida língua. Desse modo, considerando que a marcação de número ocorre apenas com uma pequena parcela dos nomes (+ humanos), pode-se hipotetizar que a pluralização não é uma propriedade distintiva entre nomes contáveis e nomes de massa em Parkatêjê.

No que concerne aos contextos em que há uma pluralidade de indivíduos, há comumente a presença de expressões indicadoras de quantidades exatas ou aproximadas, tais como: numerais e quantificadores, respectivamente. Quando tais nomes ocorrem desprovidos de qualquer marca de número e sem determinantes, isto é, como nominais nus, há uma denotação neutra no que se refere à expressão de número, singular ou plural.

Nos exemplos (14), (15) e (16), os nomes kra 'paca', piptfto 'banana'e kruwa 'flecha' aparecem despidos da marca de plural e de determinantes. Embora estruturalmente pareçam se referir a um único indivíduo, eles podem se relacionar também ao plural. 
(14)

$\begin{array}{llll}i- & t \varepsilon & k r a & \text { pupũn } \\ 1- & \text { ERG } & \text { paca } & \text { ver+PST } \\ \text { 'Eu vi } & \text { paca/pacas' }\end{array}$

$\begin{array}{llll}i- & t \varepsilon & \text { pipt } f t o & k r \tilde{e} \\ 1- & \text { ERG } & \text { banana } & \text { comer } \\ \text { 'Eu comi banana/bananas' } & \end{array}$

$\begin{array}{lllll}\text { Madalena } & \text { kruwa } & \text { pupũn } & \text { ñ̃ } & \text { puro } \\ \text { SBJ } & \text { flecha } & \text { ver+PST } & \text { LOC } & \text { logo }\end{array}$

'Madalena viu de fato flecha/flechas'

Nas construções com nomes de massa, como kwərtfom 'farinha' e mpohĩri 'carne', a quantidade também é definida contextualmente. Esses nomes não são interpretados como unidades discretas, individuadas, mas sim como porções de matéria, que são medidas com base em recipientes de medida, como o cofo, por exemplo.

$\begin{array}{llll}i- & t \varepsilon & k w a r t f o m & k r \tilde{e} \\ 1- & \text { ERG } & \text { farinha } & \text { comer }\end{array}$

'Eu comi farinha'

$\begin{array}{llll}i- & t \varepsilon & \text { mpohĩri } & k r \tilde{e} \\ 1- & \text { ERG } & \text { carne } & \text { comer }\end{array}$

Adiante, apresentaremos os quantificadores identificados em Parkatêjê e os contextos em que ocorrem.

\section{Quantificadores}

Os quantificadores, diferentemente dos numerais, expressam quantidades não tão exatas, podendo ser classificados como universais ou indefinidos. A maioria dessas expressões, em Parkatêjê, já foi descrita em trabalhos anteriores, como os de Araújo (1989 e 2016) e Ferreira (2003). Contudo, nenhum desses estudos apresenta uma análise específica dos contextos em que tais elementos ocorrem, uma vez que a perspectiva não foi a mesma adotada no presente estudo. Ademais, em alguns casos esta pesquisa diverge das descrições e classificações atribuídas a esses termos anteriormente.

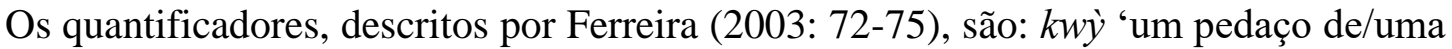
parte de'; mẽkwỳ 'alguém/alguns'; kunĩni 'todos; tudo'; mẽkunĩni 'todo mundo'; jarêtêti 'muitos'. No presente trabalho, somam-se a esses: tuti 'muito'; inkrire 'pouco'; awinti 'poucos'; jawênêre hawênêre 'pouco'; nõpyxitire 'muitos', 'grande quantidade'; e tewôti 'muitos'. Constatou-se, conforme será demonstrado no Quadro 1, que os quantificadores aqui traduzidos como 'pouco' ou 'muito' apresentam diferença. Por exemplo, nõpyxitire e tewôti expressam noção de 'muitos', mas essa noção apresenta variação, isto é, o primeiro denota grandes quantidades $(50,100$, etc.), enquanto o segundo denota, aproximadamente, 7 ou 8 unidades do elemento ao qual se refere.

Ferreira (2003: 72) considerou kuniñi/mékuniñĩ em conjunto. Na presente pesquisa, todavia, optou-se por considerá-los em separado, uma vez que a presença do formativo mé, indicativo daquilo que faz referência à natureza humana, aponta para o significado de 'todos 
(as pessoas), todo mundo', enquanto kunĩnĩ pode fazer referência a 'tudo /todo /todos', não exclusivamente ao ser humano.

Considerando os quantificadores identificados, subdividimos estes em dois grupos: universais e indefinidos ${ }^{4}$. Os quantificadores universais denotam a totalidade de um conjunto como, por exemplo, kunĩni 'todos; tudo'. Já os quantificadores indefinidos, como Kwỳ 'um pedaço de/uma parte de', denotam partes de um conjunto.

Quadro 1: Quantificadores em Parkatêjê

\begin{tabular}{|c|c|}
\hline Universais & Indefinidos \\
\hline kunĩnĩ 'todos; tudo' & $k w y ̀$ 'um pedaço de/uma parte de' \\
\hline \multirow[t]{8}{*}{ mẽkunĩñ 'todos' (+ humanos) } & mẽkwỳ 'alguém/alguns' \\
\hline & jarêtêti 'muitos' \\
\hline & tuti 'muito' \\
\hline & inkrire 'pouco' \\
\hline & awinti 'poucos' \\
\hline & jawênêre hawênêre 'pouco' \\
\hline & nõpyxitire 'muitos' (grande quantidade) \\
\hline & tewôti 'muitos' (aproximadamente 8) \\
\hline
\end{tabular}

A seguir, apresentaremos as observações acerca de cada um desses elementos.

Jarêtêti 'muitos' é utilizado para quantificar objetos cuja quantidade é superior a uma unidade, isto é, duas ou mais unidades. Nos dados, o referido quantificador pode designar diferentes quantidades, sem a especificação definida do que seja 'muito'. Trata-se, portanto, de um quantificador indefinido.

As sentenças ${ }^{5}$ (19), (20), (21) e (22) demonstram como os falantes identificaram quantidades variadas utilizando o mesmo quantificador: jarêtêti 'muitos'. Os desenhos a seguir foram mostrados e eles empregaram o mesmo quantificador nos diferentes momentos.

(19)

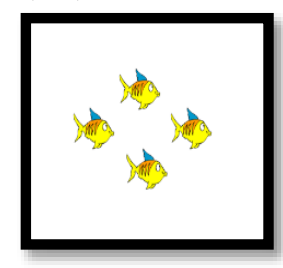

(20)

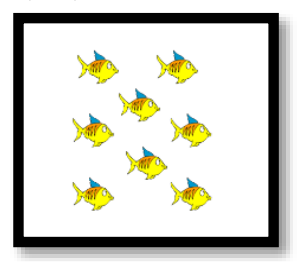

(21)

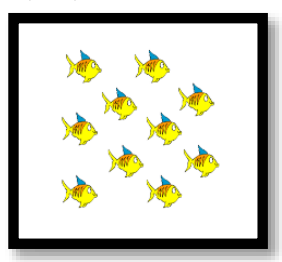

(22)

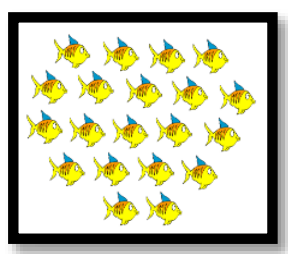

(19)

tep jarêtêti
peixe QUANT $^{6}$
'muitos peixes

'muitos peixes ${ }^{7}$,

${ }^{4}$ Ferrari-Neto (2008:52) explica que são quantificadores universais aqueles que "denotam a totalidade dos valores atribuíveis à expressão que encabeçam e apresentam uma distribuição sintática que coincide parcialmente com os D definidos, já que ambos estão sujeitos às mesmas restrições de definitude" e cita como exemplos do português os quantificadores universais: todo(s), cada, ambos e nenhum. Os quantificadores indefinidos, por sua vez, relacionam-se com os D indefinidos, como em: alguns, algum, certo, muito, pouco, tanto, outro, vários, bastante. Diferentemente dos universais, os indefinidos fazem referência a partes de um determinado conjunto.

${ }^{5}$ As sentenças e os desenhos cuja numeração é a mesma são correspondentes.

${ }^{6}$ Quantificador.

${ }^{7}$ As imagens com peixes foram fornecidas por Suzi Lima e Susan Rothstein (2020), juntamente com o questionário de distinção contável-massivo. 
(20)

tep jarêtêti

peixe QUANT

'muitos peixes'

(21) tep jarêtêti

peixe QUANT

'muitos peixes'

(22) tep jarêtêti

peixe QUANT

'muitos peixes'

Segundo os consultores, construções como (23) e (24) não ocorrem na língua, o que nos leva a considerar que jarêtêti pode ser empregado somente com nomes contáveis. Nesse sentido, seu uso pode ser considerado um critério de distinção entre nomes contáveis e nomes massivos em Parkatêjê.

$$
\begin{array}{ll}
* \text { kaprô } & \text { jarêtêti } \\
\text { sangue } & \text { QUANT }
\end{array}
$$

(24) *kô jarêtêti

água QUANT

Kwỳ foi descrito por Ferreira (2003: 72) como sendo um quantificador "cujo sentido pode ser 'vários'; 'um pouco'; 'um pedaço', dependendo do tipo de nome com o qual tal quantificador se relaciona". Trata-se, conforme a autora, de um quantificador indefinido. Em consonância, Araújo (2016: 155) afirma que $k w y$ é um partitivo que significa 'um pouco/pedaço de algo'. Um exemplo de seu emprego, em Parkatêjê, é apresentado a seguir.

(25) Parkatêjê (Ferreira 2003: 73)

$i-\quad m \tilde{a} \quad k w \dot{y}^{8}$

1- DAT QUANT

'Me dá um pedaço/pouco/um pouquinho'

Considerando-se as explicações dos consultores da língua, depreendeu-se que, de fato, a quantidade expressada por esse quantificador é variável e depende do contexto. Em outras palavras, só é possível ter a noção da quantidade expressada por $k w y$ levando-se em consideração o objeto/coisa com o qual esse quantificador está relacionado. Pedir um pedaço de melancia a alguém que está apenas com uma fatia dessa fruta é diferente, em quantidade, de pedir um pedaço dessa melancia a alguém que está com a fruta inteira. Nesse último caso, pode significar a metade da melancia, por exemplo. Assim como pedir um pouco de água a alguém que está com um copo de água é diferente, em quantidade, de pedir um pouco de água a alguém que está com um balde cheio de água. Portanto, trata-se de um quantificador que pode ser combinado com os dois tipos de entidade e seu valor semântico é definido no contexto discursivo.

\footnotetext{
${ }^{8}$ Conforme Ferreira (2003: 73), em (25) kwỳ refere-se ao núcleo nominal kuputi 'um tipo de beiju.
} 
(26)

$i-\quad m \tilde{a} \quad$ piptfo $\quad k w \grave{y}$

1- DAT banana QUANT

'Me dá um pouco de banana'

(27) $\quad i-\quad m \tilde{a} \quad k$ $\quad k w \bar{y}$

1- DAT berarubu QUANT

'Me dá um pedaço de berarubu'

(28) $\quad i-\quad m \tilde{a} \quad k \hat{o} \quad k w \grave{y}$

1- DAT água QUANT

'Me dá um pouco de água'

Mẽkwỳ 'alguns' é composto pelo formativo mẽ (marcador de plural) + o quantificador $k w y$ 'um pouco/ um pedaço'. Conforme já mencionado no tópico que trata sobre o plural na língua Parkatêjê, o formativo mẽ está relacionado ao traço [+ humano]. Os dados analisados demonstram que o referido quantificador ocorre especificamente com nomes que apresentam esse referente, mostrando-se indiferente à distinção contável-massivo.

(29) Mẽkwỳ $\quad m \tilde{u} \quad m \tilde{o}$

QUANT Q ir

'Alguns (pessoas) foram embora'

Contexto: um Parkatêjê caçou paca e o outro pediu algumas porções de carne.

(30) a. i- mã mpohĩri kwy

1- DAT carne QUANT

'Me dá um pouco de carne'

b. * $\quad$ i- mõ mpohĩri mẽkwỳ

1- DAT carne QUANT

Segundo Ferreira (2003: 72), o quantificador kunĩñ 'todo/todos' é utilizado quando relacionado a elementos não animados; já mẽkunĩn ' 'todos' é utilizado quando relacionado a elementos animados. No presente estudo, entretanto, observou-se que kunĩnĩ ocorre com nomes cujo referente é - humano, e mẽkunĩnĩ com nomes [+ humanos].

(31) kuniñ $\quad i-\quad m \tilde{a} \quad h \tilde{o}$

QUANT 1- DAT dar

'Me dá tudo (todo o berarubu)'

(32) kuniñ $\quad i-\quad m \tilde{a} \quad h \tilde{o}$

QUANT $\quad 1-\quad$ DAT dar

'Me dá tudo (todo o cupuaçu)'

(33) kunĩni $\quad i-\quad m \tilde{a} \quad h \tilde{o}$

QUANT 1- DAT dar

'Me dá tudo (toda a banana)' 
(34)

$$
\begin{array}{lcc}
\text { mẽkunĩñ } & m \tilde{u} & m \tilde{o} \\
\text { QUANT } & \mathrm{Q} & \text { ir } \\
\text { 'Todos (pessoas) foram' }
\end{array}
$$

Em (31), (32) e (33), vê-se construções com nomes cujo referente é [- humano], como kupu 'berarubu', kôtày 'cupuaçu' e piptfo 'banana', acompanhados do quantificador kunĩnĩ. Já em (34), observa-se a presença do mesmo quantificador mais o formativo mẽ. Neste último caso, nota-se que o referente é [+ humano]. Se trocarmos kunĩnĩ por mẽkunĩnĩ e vice-versa, as sentenças apresentadas anteriormente se tornarão agramaticais.

Inkrire 'pouco/pequeno' já tinha sido descrito por Araújo (1989) e Ferreira (2003) em trabalhos anteriores sobre o Parkatêjê como um adjetivo, cujo significado é 'pequeno'.

(35) Parkatêjê (Ferreira 2003: 245)

pia tfwën ati apu ayhĩ wape ane pia tfwën piti nkrire DUB $^{9}$ EVI $^{10}$ só CONT $^{11}$ dois pessoas também DUB EVI rio pequeno

'Dizem que (essas) duas pessoas viviam sós num rio pequeno'

No presente estudo, por sua vez, constatou-se que esse item lexical pode ocorrer em dois contextos distintos, ora com o sentido de 'pequeno' como descrito por Araújo e por Ferreira, ora como 'pouco'. Isto é, inkrire exerce a função de adjetivo quando combinado com nomes contáveis, e de quantificador quando combinado com nomes de massa, como podemos observar nos exemplos a seguir.

(36) kwartfom inkrire

farinha QUANT

'pouca farinha'

(37) kaprô inkrire

sangue QUANT

'pouco sangue'

(38) kô inkrire

água QUANT

'pouca água'

(39) rop inkrire

onça AJD

'onça pequena'

(40) ãhãre inkrire

galinha AJD

'galinha pequena'

(41) kwỳk inkrire

cofo AJD

'cofo pequeno'

\footnotetext{
${ }^{9}$ Dubidativo.

${ }^{10}$ Evidencial.

${ }^{11}$ Continuativo.
} 
Nomes como kwartfom 'mandioca', kaprô 'sangue' e kô 'água', cujo conteúdo é ilimitado, indiscreto, são quantificados na presença de inkrire; enquanto outros como rop 'onça', ãhare 'galinha' e kwỳk 'cofo', indivíduos com formas e limites precisos, são adjetivados como pequeno. À vista disso, podemos considerar o uso do referido quantificador como uma propriedade distintiva entre nomes contáveis e massivos.

Awinti, outro quantificador identificado, expressa noção de 'poucos', de acordo com dados coletados, em consonância com a descrição já feita por Araújo (2016: 45) sobre o Parkatêjê.

(42) Parkatêjê (Araújo 2016: 45)

Tôn jê jarêt nĩre kriure arêt nĩre irünti awinti

tatu tipo QUANT INTENS pequeno QUANT INTENS grande QUANT ${ }^{12}$

'Tatu tem muito tipo: pequenos são muitos, grandes são pouquinhos.'

Quanto aos contextos de ocorrência, constatamos que tal quantificador é sensível à distinção contável-massivo.

$$
\begin{array}{lllll}
i- & t \varepsilon & \text { petcre } & \text { awinti } & \text { pupũn } \\
1- & \text { ERG } & \text { preguiça } & \text { QUANT } & \text { ver+PST }
\end{array}
$$

'Eu vi poucas preguiças'

Contexto: Madalena tem açaí e oferece um pouco para Iracema.
a. têrêre kwỳ
açaí QUANT
'um pouco de açaí'
b. *êêre awĩnti
açaí QUANT

Em (43) e (44), temos exemplos de seu emprego com os termos petદre 'preguiça' e têrêre 'açaí', ambos aqui considerados como contável e massivo, respectivamente. Observase, por meio dos referidos exemplos, que o quantificador awinti 'poucos' ocorre com petcre 'preguiça' e com têrêre 'açaí' não. Com base nesses e em outros exemplos em que o respectivo quantificador é empregado, chegou-se à conclusão de que ele geralmente é utilizado com nomes contáveis.

Jawênêre hawênêre 'pouco' foi descrito por Araújo (2016: 64), que o considerou como um nome.

(45) Parkatêjê (Araújo 2016: 64)

$\begin{array}{llll}\text { hawênêre } & k r i ̃ & k a m & \text { kator } \\ \text { QUANT } & \text { aldeia } & \text { LOC } & \text { chegar+PST }\end{array}$

'Poucos chegaram à aldeia'

\footnotetext{
${ }^{12}$ A glosa do exemplo (42) foi inserida pelas autoras deste artigo, com base em trabalhos já publicados sobre a língua Parkatêjê.

${ }^{13}$ A glosa do exemplo (45) foi inserida pelas autoras deste artigo, com base em trabalhos já publicados sobre a língua Parkatêjê.
} 
Os primeiros dados coletados acerca desse quantificador demonstraram sua ocorrência somente com nomes contáveis, o que nos levou à conclusão de que este só é combinado com esse tipo de nome.

parkre jawênêre

canoa QUANT

'pouca canoa'

(47) kruwa jawênêre

flecha QUANT

'pouca flecha'

Entretanto, após a coleta de novos dados, constatou-se também sua ocorrência com alguns nomes de massa, como kwartfom 'mandioca' e kô 'água'. Contudo, nesses contextos, estes nomes parecem estar relacionados implicitamente a porções. Em outras palavras, esta expressão é usada para fazer referência a poucas porções de algo, ou seja, a sua cardinalidade e não a volume. Trata-se, portanto, de um quantificador que também expressa noção de 'pouco' e é usado com nomes contáveis e, em contextos específicos, com nomes de massa.

(48) $\begin{aligned} & \text { kwartfom jawênêre } \\ & \text { mandioca QUANT } \\ & \text { 'pouca mandioca' }\end{aligned}$
(49) $\begin{aligned} & \text { mpohĩri jawênêre } \\ & \text { carne } \\ & \text { 'pouca carne' }\end{aligned}$

Nõpyxitire, assim como outros quantificadores já citados, expressa noção de 'muitos' (grande quantidade). Observou-se a ocorrência do mesmo somente com nomes contáveis como, por exemplo, macaco, conforme exemplo a seguir.

$\begin{array}{lllll}i- & t \varepsilon & k \hat{k} k \hat{o} y & \text { nõpyxitire } & \text { pupũn } \\ 1- & \text { ERG } & \text { macaco } & \text { QUANT } & \text { ver+PST }\end{array}$

Contexto: alguém vai fazer berarubu e precisa de mandioca, Madalena diz que tem muito e pode dar um pouco.

$$
\begin{array}{ll}
* \text { kwartfom } & \text { nopyxitire } \\
\text { mandioca } & \text { QUANT }
\end{array}
$$

O quantificador tewôti 'muitos' foi empregado por falantes para quantidades superiores a três. Constatou-se sua ocorrência somente com elementos passíveis de contagem, ou seja, contáveis. Quando combinado com nomes de massa, como sangue, é considerado agramatical.
kenere
tewôti
pedra.pequena
QUANT
'muitas pedras' (aproximadamente 7) 


$$
\begin{array}{ll}
* \text { kaprô } & \text { tewôti } \\
\text { sangue } & \text { QUANT }
\end{array}
$$

\subsection{A ocorrência dos sufixos -re e -ti como possíveis quantificadores}

Segundo estudos realizados por Araújo (1989 e 2016), os sufixos derivacionais -re e $t i$, bem presentes em línguas Macro-Jê, família Jê, têm a função de indicar o aumentativo e o diminutivo dos nomes. A autora afirma que tais sufixos são pospostos às bases nominais, tendo natureza flexional. Ao descrevê-los, Ferreira (2003: 126) atestou que esses também ocorrem com verbos estativos e adjetivos, entretanto desempenham papel enfático nesses casos.

Araújo (1989: 28) explica que "-re está conotativamente associado a tudo que é fino, frágil, a mulher, criança e velho; - $t i$, por sua vez, se aplica a tudo que é grosso, forte, a homem e jovem".

Os referidos sufixos ainda são utilizados em termos de parentesco para indicar o que Ferreira (2003: 57) chama de "dimensão cronológica", isto é, "contraste entre a indicação de parentes mais velhos e mais novos". Ferreira (2003), assim como Araújo (1989), também considera os sufixos - $r \varepsilon$ e - $t i$ como marcadores de diminutivo e aumentativo, intensificadores e atenuantes de verbos na referida língua.

No presente estudo, observou-se a possibilidade de eles também indicarem quantidades como 'pouco' ou 'muito', ou seja, de funcionarem como quantificadores.

$$
\begin{array}{ll}
\text { kaprôti } & \text { 'muito sangue' } \\
\text { kaprôre } & \text { 'pouco sangue' }
\end{array}
$$

Conforme análise feita, esses sufixos parecem ocorrer como quantificadores somente com nomes massivos. Além disso, eles também podem, em alguns casos, indicar o estado de um determinado elemento (líquido, amassado/batido, pó, massa), conforme exemplificado a seguir.

$$
\begin{array}{ll}
\text { têrêre } & \text { 'açaí batido/amassado' } \\
\text { têrêti } & \text { 'açaí (na árvore), açaizal' }
\end{array}
$$

Com base no exemplo (57), podemos também considerar que o sufixo - $t i$ pode assumir o papel de indicador de nomes. Isto é, quando combinado com termos específicos, este, por sua vez, passa a denotar conjunto de algo, como observado em outros exemplos - (58) e (59), exercendo, portanto, a função de coletivizador de nomes.

$$
\begin{array}{ll}
\text { akrôakêtêti } & \text { 'cipozal' (Araújo 2016: 30) } \\
\text { pjêkaweti } & \text { 'plantação' (Araújo 2016: 301) }
\end{array}
$$

-re e -ti, quando combinados a alguns quantificadores como tewô 'muito', por exemplo, podem indicar quantidades distintas. Em outras palavras, há diferentes noções do que pode ser considerado muito. Assim como para falantes do português 5 não é o mesmo que 20, 50, 100, falantes de Parkatêjê também usam diferentes quantificadores para designar quantidades distintas. A diferença reside no fato de que há mecanismos específicos para isso em cada língua. O português dispõe de um sistema numérico bastante produtivo, que pode indicar com exatidão a quantidade. Em Parkatêjê, todavia, apesar de não haver um sistema numérico 
produtivo, há diversos quantificadores que dão ideia aproximada de quantidade. Jarêtêre, por exemplo, significa 'muitos', mas representa menos que jarêtêti 'muitos'. Isto é, ambos apresentam o sentido 'grande quantidade', mas o primeiro representa menor quantidade em relação ao segundo. São quantificadores iguais, mas, quando combinados aos sufixos $-r \varepsilon \mathrm{e}-t i$, tomam proporções distintas em relação umas às outras.

$$
\begin{array}{lll}
\text { a. jarêtêre 'muitos' } & \\
\text { b. jarêtêti } & \text { 'muitos' }
\end{array}
$$

(61) a. tewôre 'muitos'

b. tewôti 'muitos'

Ademais, tais sufixos, principalmente $-t i$, ocorrem com muitos nomes abstratos, como nos exemplos seguintes, aparentando ser muito semelhante, semanticamente, aos intensificadores.

(62) $i-\quad m \tilde{a} \quad p r a ̃ m-t i$

1- DAT ter.fome-QUANT

'Eu estou com muita fome'

(63) $\quad i-\quad m \tilde{a} \quad k o r u-t i$

1- DAT sede-QUANT

'Eu estou com muita sede'

A próxima seção é dedicada à discussão sobre a ausência de classificadores e a presença de termos de classe em Parkatêjê.

\section{Classificadores}

Em consonância com Ferreira (2003: 221), não identificamos a ocorrência de classificadores na referida língua. Conforme esclarecido pela autora, a língua Parkatêjê "apresenta um conjunto de termos que funcionam como formativos classificatórios e que são constituídos basicamente de uma sílaba”. Ao serem combinados com outras raízes nominais, formam-se compostos: nome específico + nome genérico.

Parkatêjê (Ferreira 2003: 221)

(64) ko 'indicativo de frutos que dão em cachos'

(65) rõti-ko 'cocal'

(66) kapere-ko 'bacabal'

(67) têrêre-ko 'açaizal'

(68) awara-ko 'anajazal'

Ferreira (2003: 221) não os considera como classificadores pela seguinte razão:

os termos de classe são nomes que fazem parte de um grupo semântico, cujos traços comuns podem ser definidos pelas propriedades físicas a que fazem referência. Esses termos são restritos a poucos campos lexicais, o que os diferencia de classificadores nominais, que cobrem mais extensivamente o léxico. (Ferreira 2003: 221) 
Ou seja, a ocorrência desses elementos abrange somente uma pequena parcela dos nomes, o que os aproxima de termos de classe. Estes parecem indiferentes à distinção contávelmassivo.

Na próxima seção, abordaremos as construções de recipiente em Parkatêjê. Conforme será discutido, algumas dessas expressões são constituídas por nomes que designam utensílios muito utilizados em contextos de contagem e medição.

\section{Expressões e recipientes de medida}

Na presente pesquisa, não foram identificadas expressões de medida, a exemplo de, em português, metro, quilo etc. Observou-se a indicação de formas de quantificar recipientes de medida. Em grande parte, essas expressões incluem nomes de utensílios importantes para medição de massas, líquidos e grãos em Parkatêjê. Estes, considerados na maioria das línguas como massivos, necessitam comumente de um recipiente para sua medição, haja vista que são compostos, conforme discutido na literatura, por massa ilimitada, material indiferenciado. Nesse sentido, diante da impossibilidade de contagem dos mesmos, na maioria dos casos, isto é, de sua combinação direta com numerais, os recipientes são utilizados como intermediadores entre nomes e numerais. Ou seja, por meio de seu emprego, nomes podem ser contados.

$\mathrm{Na}$ referida língua, são utilizados como recipientes de medida tanto artefatos feitos pelos próprios indígenas com recursos naturais, como o cofo e cestos (em geral), quanto aqueles que são encontrados na natureza, como a cabaça, a cuia e o cupuaçu. As figuras a seguir demonstram alguns desses recipientes.

Figura 1. Cesto (artefato tradicional)

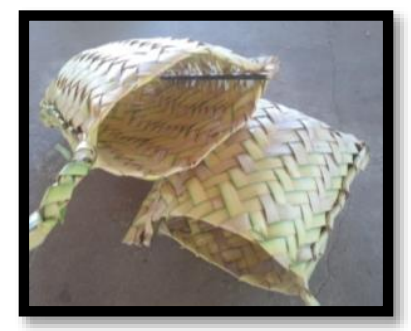

Figura 3. Cuia

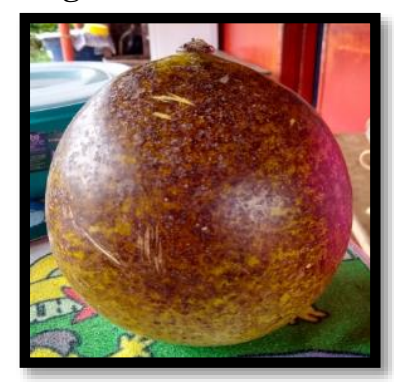

Figura 2. Cofo (artefato tradicional)

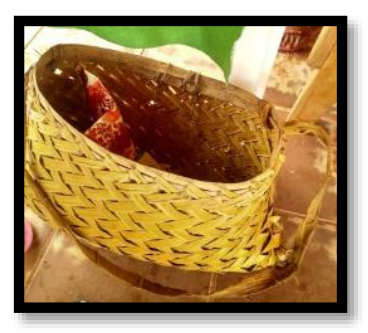

Figura 4. Cuia

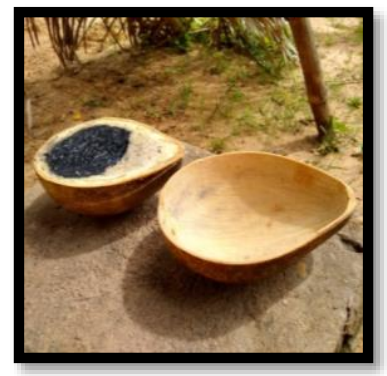

De acordo com os entrevistados, para armazenar massas, frutas, artefatos, legumes e verduras, eles utilizam o cofo e cestos (em geral). Já para armazenar líquidos, como água, mel, eles utilizam a cabaça, a casca do cupuaçu e cortes de varas de bambu. 
Figura 5. Cabaça

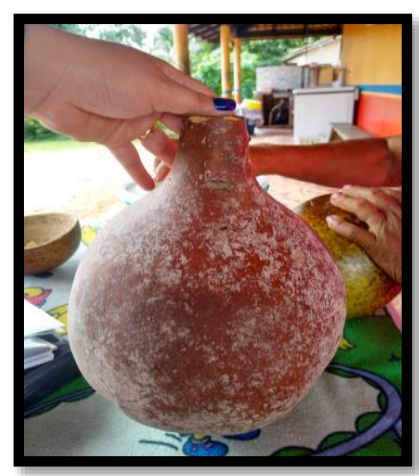

Figura 6. Bambueiro

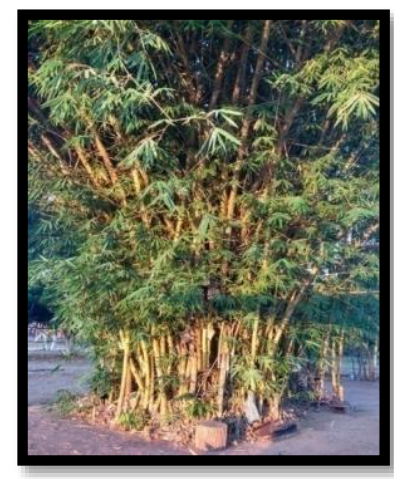

Figura 7. Cupuaçu

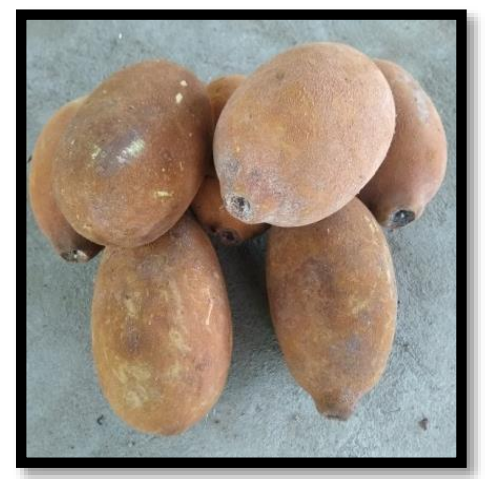

As imagens apresentadas acima foram registradas pelas autoras deste trabalho durante as coletas de dados realizadas nas aldeias Parkatêjê.

Discutiremos adiante os resultados deste estudo e os critérios identificados, em Parkatêjê, para distinguir nomes contáveis e nomes massivos.

\section{Discussão dos resultados}

A noção do que é contável ou massivo varia de uma língua para outra. Em inglês, por exemplo, hair 'cabelo' é massivo, enquanto no francês é contável, cheveux 'cabelos'. Assim como fruta, em português, é contável, mas, em inglês, é massivo, fruit 'fruta', conforme Paraguassu-Martins e Muller (2007: 71). Nesse sentido, faz-se necessário um estudo cuidadoso para distinguir e descrever os critérios que determinada língua utiliza nessa distinção.

Em Parkatêjê, observou-se que os nomes podem ser distribuídos em dois grupos distintos: um constituído por nomes contáveis, isto é, aqueles que podem ser contados em unidades; e o outro, composto pelos nomes que denotam massa, conteúdo incontável. Percebeu-se que esses grupos se diferem, principalmente, pela combinação com os seguintes elementos: quantificadores e numerais. Logo, estes foram os critérios adotados para distinguir quais nomes na língua podem ser considerados contáveis e quais podem ser tidos como massivos.

De forma resumida, temos a seguir um quadro que demonstra a possibilidade ou não de ocorrência desses quantificadores e numerais combinados com nomes contáveis e massivos. 
Quadro 2: Expressões de quantidade ${ }^{14}$

\begin{tabular}{|c|c|c|}
\hline Expressões de quantidade & Nomes contáveis & Nomes de massa \\
\hline pitfit 'um' & $\checkmark$ & 0 \\
\hline ajkrut 'dois' & $\checkmark$ & 0 \\
\hline hitô 'três' & $\checkmark$ & O \\
\hline$k w \grave{y}$ 'um pedaço de/uma parte de' & $\checkmark$ & $\checkmark$ \\
\hline mékwỳ 'alguém/alguns' [+ humanos] & 0 & \\
\hline kuniñ 'todos, tudo,' & $\checkmark$ & $\checkmark$ \\
\hline mékunĩni 'todos' [+ humanos] & 0 & \\
\hline jarêtêti 'muitos' & $\checkmark$ & \\
\hline tuti 'muito', & & $\checkmark$ \\
\hline inkrire 'pouco', & $\checkmark$ & $\checkmark$ \\
\hline awinti 'poucos' & $\checkmark$ & \\
\hline jawênêre hawênêre 'pouco' & $\checkmark$ & 0 \\
\hline nópyxitire 'muitos' (grande quantidade) & $\checkmark$ & \\
\hline tewôti 'muitos' (aproximadamente 7/8) & $\checkmark$ & \\
\hline
\end{tabular}

Os dados demonstram que as expressões de quantidades na língua, tais como: quantificadores e numerais, são condicionadas pelo tipo de nome. Em outras palavras, essas expressões são selecionadas para serem combinadas com determinados nomes considerando a sua tipologia, isto é, se contável ou massivo. Algumas delas ocorrem com ambos como, por exemplo, kwỳ 'pouco'; entretanto há também as que são combinadas somente com nomes contáveis, como jarêtêti 'muitos', e outras com somente nomes de massa, como tuti 'muito'.

Ao analisar o acervo de dados, observamos que, lexicalmente, não há como se prever se um nome é contável ou de massa. A distinção pode ser percebida por meio das combinações destas palavras com numerais e quantificadores. A referida língua, conforme análise, não apresenta classificadores.

Considerando a análise e descrição demonstrada neste trabalho, podemos considerar que a língua Parkatêjê desafia a proposta de Chierchia (2010), uma vez que dispõe de alguns traços tanto das línguas de marcação de número quanto das línguas de número neutro. Em Parkatêjê, assim como em muitas línguas de marcação de número, os numerais podem ser combinados diretamente com nomes contáveis e, em contextos específicos, com nomes de massa. Ademais, a referida língua apresenta quantificadores que ocorrem com todos os nomes e outros específicos que só ocorrem com nomes contáveis, ou com nomes de massa. O que difere Parkatêjê de outras línguas de marcação de número é justamente o plural, pois nela tal propriedade não é significativa quanto à distinção entre tais nomes. Embora haja um formativo marcador de plural, $m \tilde{e}$, este ocorre apenas com uma pequena parcela dos nomes. Nos casos em que ele não está presente e os nomes estão nus, a denotação é neutra em relação ao número. Ou seja, os nomes, nesse caso, podem ser interpretados tanto no singular quanto no plural. Logo, conclui-se que o plural ocorre especificamente com nomes cujo referente é + humano, mostrando-se indiferente à distinção contável vs. massivo.

Ademais, Parkatêjê também apresenta um traço semelhante ao das línguas de número neutro, isto é, difere nomes contáveis e massivos por meio do uso de numerais (tal como as línguas de número marcado) e, crucialmente, apresenta nomes nus em posição argumental.

14 Legenda:

$\checkmark$ Ocorre.

- Ocorre somente em contextos específicos. Por exemplo, quando um falante se refere à quantidade de recipientes de medida e não ao nome massivo propriamente dito.

Sem marcação: indica que não foram observadas ocorrências em nenhuma situação. 


\section{Considerações finais}

Este estudo teve como finalidade analisar e descrever o comportamento de nomes em Parkatêjê, objetivando verificar se essa língua distingue seu grupo nominal em contáveis e massivos. Constatou-se que há distinção entre os nomes no que se refere à contabilidade e que esta é feita por meio de critérios na utilização de numerais e quantificadores. Não foi observada a ocorrência de classificadores, mas, sim, de termos de classe, sendo este indiferente à distinção contável-massivo.

Os numerais pitfit 'um', ajkrut 'dois' e hitô 'três' podem ser combinados diretamente com nomes contáveis, enquanto para ocorrerem com nomes massivos, esses necessitam da presença de um recipiente de medida, ou que este esteja subentendido no contexto.

Apesar de não dispor de um sistema numérico muito produtivo, Parkatêjê apresenta

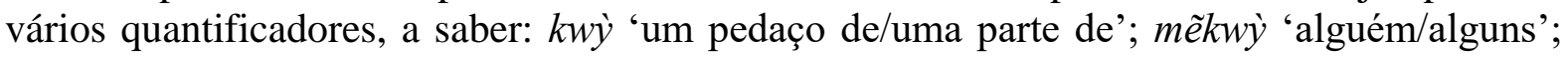
Kunĩni 'todos, tudo,'; mẽkunĩnĩ 'todos'; jarêtêti 'muitos'; tuti 'muito'; inkrire 'pouco'; awĩnti 'poucos'; jawênêre hawênêre 'pouco'; e tewôti 'muitos'. Essas expressões de quantidade não ocorrem de forma aleatória, há aqueles que podem ser combinados com qualquer nome, enquanto outros são usados especificamente com nomes contáveis, como jarêtêti 'muitos', e outros apenas com nomes massivos, como tuti 'muito'.

Considerando os resultados alcançados, chegou-se à conclusão de que a língua Parkatêjê não se enquadra, especificamente, em nenhuma das tipologias propostas por Chierchia (2010). Ela apresenta alguns traços das línguas de marcação de número, como a distinção contável-massivo por meio de numerais e quantificadores, assim como traços das línguas de número neutro, haja vista que a marcação de número, nessas línguas, é inexistente e, portanto, não é um critério para distinguir os nomes contáveis e massivos; neste último tipo de língua, a distinção pode ser percebida por meio do uso de numerais e também se observa nomes nus em posição argumental. Nesse sentido, constata-se que Parkatêjê mescla algumas características desses dois tipos de língua, mas que são insuficientes para enquadrá-la num ou noutro tipo.

Como este é um estudo pioneiro, não foi possível fazer comparações com outras línguas da família Jê. E pelo fato de o Parkatêjê já se encontrar em estado de obsolescência linguística, não foi possível avançar na pesquisa dos sintagmas de medida, outrora empregados no universo cultural dessa língua indígena.

\section{Referências}

Araújo, Leopoldina Maria Souza de (1977). Estruturas subjacentes de alguns tipos de frases declarativas afirmativas do dialeto Gavião Jê (Dissertação de mestrado em linguística). Florianópolis: Departamento de Língua e Literatura Vernácula, Universidade Federal de Santa Catarina.

Araújo, Leopoldina Maria Souza de (1989). Aspectos da língua Gavião-Jê (Tese de doutorado em linguística). Rio de Janeiro: Faculdade de Letras, Universidade Federal do Rio de Janeiro.

Araújo, Leopoldina Maria Souza de (2016). Dicionário Parkatêjê-Português. Belém: Edição da Autora.

Chierchia, Gennaro (2010). Mass nouns, vagueness and semantic variation. Synthese 174(1): 99-149. https://doi.org/10.1007/s11229-009-9686-6

Cruse, Alan (2011). Meaning in language: An introduction to semantics and pragmatics. 3rd. edn. United Kingdon: Oxford University Press. 
Ferrari-Neto, José (2008). Aquisição de número gramatical no português brasileiro: Processamento de informação de interface e concordância (Tese de doutorado). Rio de Janeiro: Pontifícia Universidade Católica de São Paulo.

Ferreira, Marília de Nazaré de Oliveira (2003). Estudo morfossintático da língua Parkatêjê (Tese de doutorado em linguística). São Paulo: Instituto de Estudos da Linguagem, Universidade Estadual de Campinas. http://repositorio.unicamp.br/jspui/handle/REPOSIP/270362

Lima, Suzi (2014). The grammar of individuation and counting (Ph.D. dissertation). Amherst: University of Massachusetts.

https://scholarworks.umass.edu/cgi/viewcontent.cgi? article=1051\&context=dissertations 2

Lima, Suzi; Rothstein, Susan (2020). A typology of the mass/count distinction in Brazil and its relevance for mass/count theories. Linguistic Variation 20(2): 174-218. https://doi.org/10.1075/lv.00015.lim

Rothstein, Susan; Lima, Suzi (2018). Quantity evaluations in Yudja: Judgements, language and cultural practice. Synthese: 1-23. https://link.springer.com/article/10.1007/s11229-018-02016-5

Paraguassu-Martins, Nize; Müller, Ana (2007). A distinção contável-massivo e a expressão de número no sistema nominal. DELTA: Documentação de Estudos em Linguística Teórica e Aplicada 23(SPE): 65-83. https://www.scielo.br/pdf/delta/v23nspe/v23nspea06.pdf

Rodrigues, Aryon Dall'Igna (1986). Línguas brasileiras: Para o conhecimento das línguas indígenas. São Paulo: Loyola.

Recebido: $2 / 10 / 2020$

Versão revista $1: 5 / 5 / 2021$

Versão revista 2: 16/05/2021

Versão revista final: 30/5/2021

Aceito: 3/6/2021

Publicado: 7/6/2021 